\title{
Experimental and analytical study of concrete blocks subjected to concentrated loads with an application to TBM-constructed tunnels
}

\begin{abstract}
To generate enough thrust for a Tunnel Boring Machine (TBM) to excavate a soil and advance, several jacks are typically used to apply force to the last installed ring that acts as a reaction frame. These loads generate bursting stresses that might cause cracks in the longitudinal direction of the segments. Many studies dedicated to evaluating this phenomenon focus mainly on elements with similar height-to-length ratios. To cover the wide variety of dimensions and load application patterns, additional experimental assessments are required. The objectives of the present paper are to extend the study of with different height-to-length ratios subjected to concentrated loads and to validate analytical formulations for the verification of concrete segments in SLS and ULS. To accomplish this, an experimental program was constructed using small-scale specimens with and without fibre reinforcement. The results obtained were used to validate the formulations derived from a struts-and-ties model. Finally, an application of the formulation proposed to the case study of Line 9 in Barcelona is presented. This study represents a contribution towards the development of simplified tools for the design of segmented linings both in the SLS and in the ULS.
\end{abstract}

\section{Keywords}

concentrated load, precast segment, crack pattern, strut and tie model, structural design 


\section{Introduction}

To generate enough thrust for a Tunnel Boring Machine (TBM) to excavate soil and advance, several jacks are typically used to apply force to the last installed ring that acts as a reaction frame. If the loads are excessively high, crack patterns might arise in traditionally reinforced and in fibre reinforced concrete segments, as presented in Figure 1 [1] for different configurations of the thrust jacks. Although some of the cracks might be explained by an imperfect support of the segments [2-4], others are related to the application of concentrated loads. In the latter case, compressive and splitting stresses appear under the pads of the jacks. These stresses are derived from a triaxial state that spreads over the disturbance zone through compression trajectories. These trajectories are internally balanced by tensile trajectories, leading to splitting stresses (i.e., bursting stresses) that cause the main vertical cracks through the depth of the segment. Similarly, as a result of the convexdeformed geometry, spalling stresses could appear and generate secondary cracks.
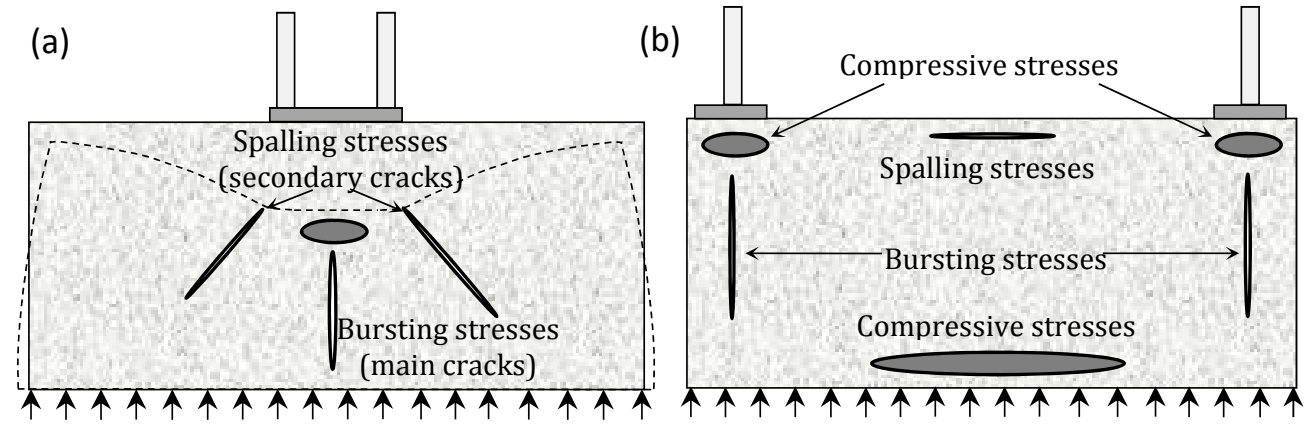

Figure 1. General stress patterns for different thrust jack's configurations: (a) German; and (b) Japanese and French systems.

Even though the opening of secondary cracks should also fulfil the service limit state (SLS) requirements, bursting stresses are of special interest to the design of the structure because they determine the reinforcement strategy. Currently, these crack patterns (Figure 1) are typically controlled by using traditional steel bars. However, it has been proven that the use of a certain amount of structural fibres may enhance the performance in SLS [5], leading to cost and time savings [6].

It is well known that the application of concentrated loads induces a complex 3-D state of stresses, which is difficult to evaluate due to the existence of a disturbance zone beneath the load transfer area. The phenomenon was initially evaluated and applied to support systems [7-9] and pre-stress transfer zones [10]. Investigations for the particular case of tunnels constructed with a TBM and concrete segments [1, 3, 11-12] are also in the literature. Table 1 gathers experimental programs from the literature related to the behaviour of concrete elements subjected to concentrated loads.

The studies presented in Table 1 comprise concrete blocks (B) and precast concrete segments (PS). Some of these studies examined real tunnels (e.g., the Barcelona Metro Line 9 in Spain [15], Hydraulic Tunnel of Montelirio in Panama [17, 20], the Brenner Base Tunnel joining Italy and Austria [21] and the Prague Metro Line [21-22]), while the rest are associated with research projects [13-14, 18, 23-24]). Others also include plain concrete (PC), 
reinforced concrete (RC) or fibre reinforced concrete elements.

Table 1. Previous research focused on FRC elements subjected to concentrated loads

\begin{tabular}{|c|c|c|c|c|c|c|c|c|c|}
\hline Elements & $\begin{array}{c}\mathrm{f}_{\mathrm{c}} \\
(\mathrm{MPa})\end{array}$ & $\begin{array}{l}\text { Dimensions } \\
(\mathrm{mm})\end{array}$ & Material & $\begin{array}{c}\mathrm{C}_{\mathrm{f}} \\
\left(\mathrm{kg} / \mathrm{m}^{3}\right)\end{array}$ & $\Phi_{\mathrm{f}} / \lambda_{\mathrm{f}}$ & Tests & Load & $\begin{array}{l}\text { Numerical } \\
\text { simulation }\end{array}$ & Ref. \\
\hline \multirow{3}{*}{$\begin{array}{l}\text { PS } \\
\text { (RP) }\end{array}$} & \multirow{3}{*}{60} & \multirow{3}{*}{$\begin{array}{l}\text { 3000x1000x300 } \\
\text { (panels) }\end{array}$} & $\mathrm{RC}$ & - & - & \multirow{3}{*}{4} & \multirow{3}{*}{ Centred jack } & \multirow{3}{*}{ 3D-FE (ANSYS) } & \multirow{3}{*}{ [13] } \\
\hline & & & \multirow[b]{2}{*}{ SFRC } & 35 & $0.65 / 60$ & & & & \\
\hline & & & & 60 & $\begin{array}{l}0.65 / 60 \\
0.92 / 65\end{array}$ & & & & \\
\hline \multirow{2}{*}{$\begin{array}{c}\mathrm{B} \\
(\mathrm{RP})\end{array}$} & \multirow{2}{*}{60} & \multirow{2}{*}{$350 \times 350 \times 700$} & \multirow{2}{*}{ SFRC } & 35 & \multirow{2}{*}{$\begin{array}{l}0.65 / 60 \\
0.92 / 60\end{array}$} & \multirow{2}{*}{12} & \multirow{2}{*}{$\begin{array}{l}\text { Centred line and } \\
\text { point loads }\end{array}$} & \multirow{2}{*}{$\begin{array}{c}\text { (1) 3D-FE (ANSYS) } \\
\text { and (2) strut-tie } \\
\text { models }\end{array}$} & \multirow{2}{*}{ [14] } \\
\hline & & & & 60 & & & & & \\
\hline \multirow{2}{*}{$\begin{array}{c}\text { PS } \\
\text { (MT) }\end{array}$} & \multirow{2}{*}{50} & \multirow{2}{*}{$\begin{array}{l}\text { 900x520x175 } \\
\text { (panels) }\end{array}$} & $\mathrm{RC}+\mathrm{SFRC}$ & 30 & \multirow{2}{*}{$1.00 / 65$} & \multirow{2}{*}{4} & \multirow{2}{*}{$\begin{array}{c}\text { Centred \& } \\
\text { eccentric jack }\end{array}$} & \multirow{2}{*}{$\begin{array}{c}\text { 3D-FE elastic } \\
\text { model (ANSYS) }\end{array}$} & \multirow{2}{*}{ [15] } \\
\hline & & & SFRC & 60 & & & & & \\
\hline \multirow{2}{*}{$\begin{array}{l}\text { PS } \\
\text { (RP) }\end{array}$} & \multirow[b]{2}{*}{$75-100$} & \multirow[b]{2}{*}{$3150 \times 1420 \times 300$} & $\mathrm{RC}$ & - & - & \multirow[b]{2}{*}{5} & \multirow[b]{2}{*}{ Centred jack } & (1) 3D-FE & \\
\hline & & & SFRC & 60 & $1.00 / 50$ & & & $\begin{array}{l}\text { (2)strut-tie } \\
\text { models }\end{array}$ & [16] \\
\hline $\begin{array}{l}\text { PS } \\
(\mathrm{HT})\end{array}$ & 35 & 1840x1200x250 & SFRC & 40 & $0.75 / 80$ & 1 & Centred jack & None & [17] \\
\hline & & & $\mathrm{PC}$ & - & - & & Centred jack on & & \\
\hline $\begin{array}{l}\text { PS } \\
\text { (RP) }\end{array}$ & 60 & $2359 \times 1400 \times 350$ & SPFRC & $30+1$ & $\begin{array}{c}0.75 / 80 \\
+\end{array}$ & 9 & $\begin{array}{c}\text { cantilevered } \\
\text { supported }\end{array}$ & None & [18] \\
\hline & & & स & $40+1$ & PP fibres & & segment & & \\
\hline PS & 50 & $3400 \times 1500 \times 200$ & $\mathrm{RC}$ & - & - & & & & \\
\hline$(\mathrm{RT})$ & 50 & $3400 \times 1500 \times 200$ & SFRC & 40 & $0.35 / 85$ & 2 & Centred jack & None & [19] \\
\hline & & & & & $0.35 / 85$ & & & & \\
\hline (HT) & 35 & 1840x1200x250 & SFRC & 40 & $0.60 / 50$ & 3 & Centred jack & MC2010 & [20] \\
\hline $\begin{array}{l}\text { PT } \\
\text { (MT) }\end{array}$ & 60 & $2570 \times 1500 \times 250$ & SFRC & 40 & $0.75 / 40$ & 15 & $\begin{array}{l}\text { Centred jack on } \\
\text { uniformly and } \\
\text { cantilevered }\end{array}$ & $\begin{array}{c}\text { (1) 2D-FE } \\
\text { (ATENA) and (2) } \\
\text { 3D-FE for the full- }\end{array}$ & $\begin{array}{l}{[21]} \\
{[22]}\end{array}$ \\
\hline & & & & 50 & $0.75 / 80$ & & $\begin{array}{c}\begin{array}{c}\text { supported } \\
\text { segment }\end{array} \\
\end{array}$ & $\begin{array}{c}\text { scale tests on } \\
\text { precast segments }\end{array}$ & \\
\hline & & & $\mathrm{PC}$ & - & - & & & & \\
\hline & & & & 40 & & & $\begin{array}{l}\text { Difrerent loaded- } \\
\text { area ratios with }\end{array}$ & & \\
\hline B & & & & 60 & $0.75 / 80$ & & varying positions & & \\
\hline (RP) & 75-95 & $300 \times 150 \times 150$ & SFRC & 80 & & 96 & of the & 3D-FE (MSC-Marc) & [23] \\
\hline & & & & 60 & $\begin{array}{l}0.90 / 65 \\
0.71 / 85\end{array}$ & & concentrated & & \\
\hline & & & & & $0.55 / 55$ & & & & \\
\hline PS & $150-170$ & 1000x500x100 & UHPC & - & - & 2 & Centred TBM & None & [24] \\
\hline$(\mathrm{RP})$ & & (reduced scale) & UHSFRC & 236 & $0.20 / 80$ & 2 & jack simulation & & \\
\hline
\end{tabular}

PS: precast concrete segment; B: concrete block; RP: research project; MT: metro tunnel; HT: hydraulic tunnel; RT: road tunnel; RC: reinforced concrete; SFRC: steel fibre reinforced concrete; PC: plain concrete; $C_{f}$. amount of fibres; $\Phi_{f:}$ diameter of the fibre; and $\lambda_{f}$ slenderness ratio of the fibre.

In general, the forces from a TBM's thrust jacks were emulated in the experimental programs from Table 1 as centred loads applied by laboratory testing machines, except in [15] and [23], which also included the eccentricity of the load as a parameter. Although in most cases the elements were uniformly supported, several authors [18, 21-22] tested an imperfect support between a placed ring and a segment being installed with a cantilevered configuration. Conversely, [23] analysed the effect of different loaded area ratios and positions of the load.

The influence of the diameter $\left(\Phi_{f}\right)$ and aspect ratio $\left(\lambda_{f}\right)$ of the fibres were studied in 
several experimental programs. Both parameters ranged from $0.20 \mathrm{~mm}$ to $1.00 \mathrm{~mm}$ and from 40 to 85, respectively. In almost all tests except for [18], steel fibres with hooked ends and amounts ranging from 35 to $80 \mathrm{~kg} / \mathrm{m}^{3}$ were used. Effects on the variability on the structural response due to the fibre distribution and orientation were studied by [16] and [23]. A special mention should be made to the experimental program conducted by [24] to evaluate the ultra-high performance steel fibre reinforced concrete (UHPSFRC) as a potential material to enhance both the mechanical and durability performance of tunnel segments. In that study, UHPSFRCs with compressive strengths from 150 to $170 \mathrm{~N} / \mathrm{mm}^{2}$ and $236 \mathrm{~kg} / \mathrm{m}^{3}$ (3\% by volume) of straight steel fibres were studied.

Concerning the design, it should be noted that 3D finite element models with smeared crack has been the primary approach used by researchers [13-16, 21-24] to simulate the jack thrust of a TBM numerically. The most common software packages applied for this purpose were ABAQUS [25], ANSYS [26], ATENA [27] and MSC-Marc [28] (see Table 1). Other numerical studies have been performed by [29] and [30] in which different fibre reinforcement ratios and load configurations were evaluated. Particularly, in [29], a real failure of a segment used at the Metro Line 9 of Barcelona was reproduced numerically.

Analytical models based on the struts and ties models (STMs) have also been recommended as a safe alternative to evaluate the splitting stresses and the reinforcement requirements of element subjected to concentrated loads [31-33], particularly for precast concrete segments [34-38]. This simplified approach is interesting due to its easy implementation and adaptability to reproduce the stress patterns caused by TBM thrust. In [14], a study was performed to adjust the analytical expressions considering the fibre contribution in the resistant mechanism as well as to adjust the depth of the disturbance zone.

Despite the many studies in the literature, most study elements with similar height-tolength ratios. To cover the wide variety of dimensions and loading patterns, additional experimental assessments are yet required. These studies could support the calibration of analytical formulations to assess the cracking and the failure load depending on the dimensions of the elements.

The objective of the present paper is to extend the study of elements subjected to concentrated loads by considering different height-to-length ratios with and without fibre reinforcement. The goal of this study is to validate simplified analytical formulations that may be applied for the verification of concrete segments in SLS and ULS. An experimental program was also conducted with small-scale specimens; the associated results were used to validate the formulations derived using similar studies from the literature. Finally, an application of the formulation is proposed to the case study of Line 9 in Barcelona is presented. This study represents a contribution toward the development of simplified tools for the design of SLS and ULS segmented linings.

\section{EXPERIMENTAL PROGRAM}

The experimental program consisted of the assessment of the mechanical response of small-scale concrete specimens with different dimensions subjected to concentrated loads. To consider the typical variety of materials applied in segmented linings, specimens were cast with 4 concrete series with the compositions indicated in Table 2. The series PC-40 and PC- 
50 correspond to plain concrete with compressive strengths [39] $\left(f_{c}\right)$ of $40 \mathrm{~N} / \mathrm{mm}^{2}$ and 50 $\mathrm{N} / \mathrm{mm}^{2}$, respectively. The series SFRC-40 and SFRC-50 correspond to steel-fibre-reinforced concrete with equivalent strength class. Hooked-end steel fibres with $60 \mathrm{~mm}$ of length $\left(I_{f}\right)$, $0.75 \mathrm{~mm}$ of diameter $\left(\Phi_{f}\right)$ and yield modulus $\left(f_{f}\right)$ of $1050 \mathrm{~N} / \mathrm{mm}^{2}$ were used in the latter type.

Table 2. Composition of concrete series (in $\mathrm{kg} / \mathrm{m}^{3}$ )

\begin{tabular}{lcccc}
\hline \multicolumn{1}{c}{ Material } & PC-40 & SFRC-40 & PC-50 & SFRC-50 \\
\hline Cement CEM I 52,5R & 300 & 300 & 400 & 400 \\
Marble powder & 350 & 350 & 250 & 250 \\
Sand 0-3 (mm) & 510 & 510 & 510 & 510 \\
Aggregate 2.5/6 (mm) & 400 & 400 & 400 & 400 \\
Aggregate 6/15 (mm) & 520 & 520 & 520 & 520 \\
ADVA Flow 400 & 12 & 12 & 12 & 12 \\
Water & 150 & 150 & 178 & 178 \\
Steel fibres & - & 40 & - & 40 \\
\hline
\end{tabular}

In total, 32 concrete blocks were cast with the dimensions shown in Figure 2. In this sense, $\boldsymbol{a}, \boldsymbol{b}$ and $\boldsymbol{h}_{T}$ represent the length, width and height of the concrete blocks, respectively. $\boldsymbol{a}_{1}, \boldsymbol{b}_{1}$ and $\boldsymbol{h}_{1}$ correspond to the length, width and height of the support plate, respectively. The concrete was poured directly into a four-compartment mould (see Figure 3a) placed on a vibrating table. As shown in Figure 3b, metal bushings were installed on both sides of the larger moulds.

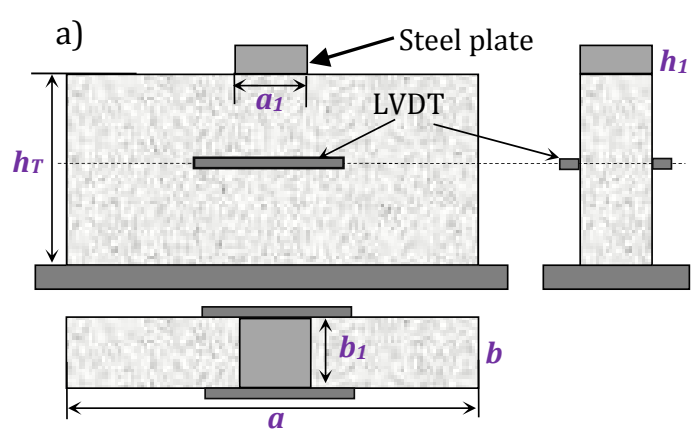

b)

\begin{tabular}{|c|c|c|c|c|c|}
\hline$a$ & $a_{1}$ & $b$ & $b_{1}$ & $h_{T}$ & $h_{1}$ \\
\hline 200 & $150^{*}$ & 150 & 150 & 300 & 50 \\
\hline 250 & $150^{*}$ & 150 & 150 & 300 & 50 \\
\hline 400 & 150 & 150 & 150 & 300 & 50 \\
\hline 750 & 150 & 150 & 150 & 300 & 50 \\
\hline
\end{tabular}

* For the series SFRC40 with the length $a=200$ and $250 \mathrm{~mm}$, the width of the plate is $\boldsymbol{a}_{1}=50 \mathrm{~mm}$.

Figure 2. (a) Three-view plan schematic of the instrument set-up; and (b) dimensions of the blocks and support plates.

In addition to the elements used in the concentrated load tests, 12 cylindrical specimens $(\Phi 15 \times 30 \mathrm{~cm}), 12$ cylindrical specimens $(\Phi 15 \times 30 \mathrm{~cm})$ and 16 cylindrical specimens $(\Phi 15 \times 15 \mathrm{~cm})$ were cast and used to assess the compressive and tensile strengths using the Brazilian test [40] and the residual using the Barcelona test [41-43], respectively. All specimens were produced on the same day in the same ambient conditions. The specimens were stored under controlled conditions at a temperature of $20 \pm 1{ }^{\circ} \mathrm{C}$ and an average relative humidity HR $\geq 95 \%$ until testing.

During the tests, the blocks were supported by a rigid steel plate, and the load was applied by the system presented in Figure 4. Similarly, two Temposonic displacement sensors were fastened to the block in a horizontal orientation at the middle on both sides. The loading 
rate was $0.2 \mathrm{MPa} / \mathrm{s}$, and the tests were stopped once failure was detected.

3. TEST RESULTS AND ANALYSIS

Table 3 shows the results of the characterization tests carried out 28 days after casting. $f_{c m}$ is the average compressive concrete strength, and $f_{c t m 1}$ and $f_{c t m 2}$ are the average tensile strengths obtained from the Barcelona and Brazilian tests, respectively.

a)
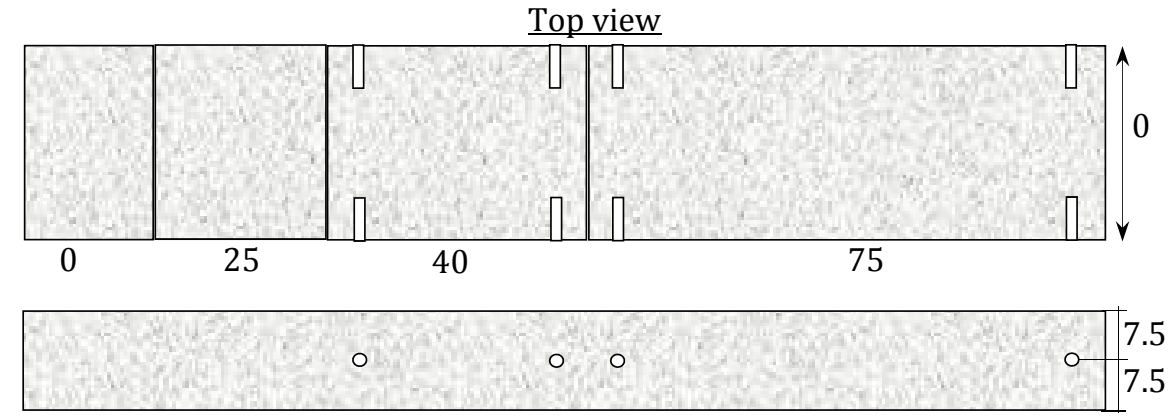

Lateral view

b)
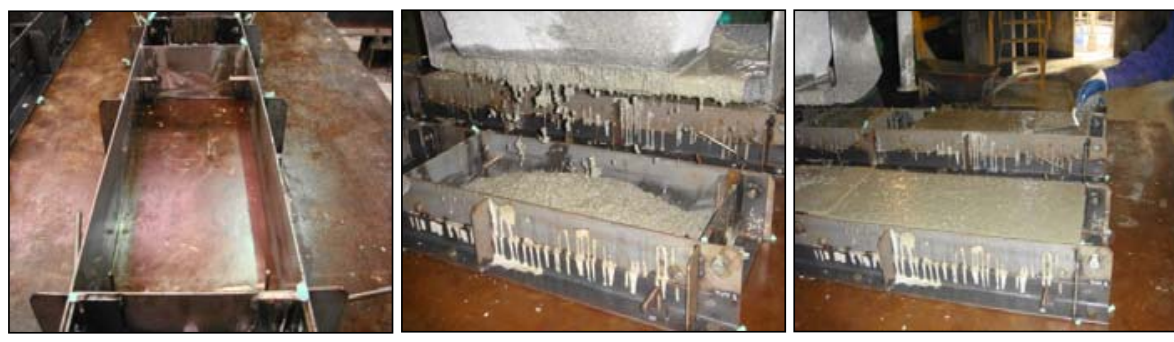

Figure 3. Production of the concrete blocks: (a) dimensions of the moulds (in mm); and (b) different views during casting.
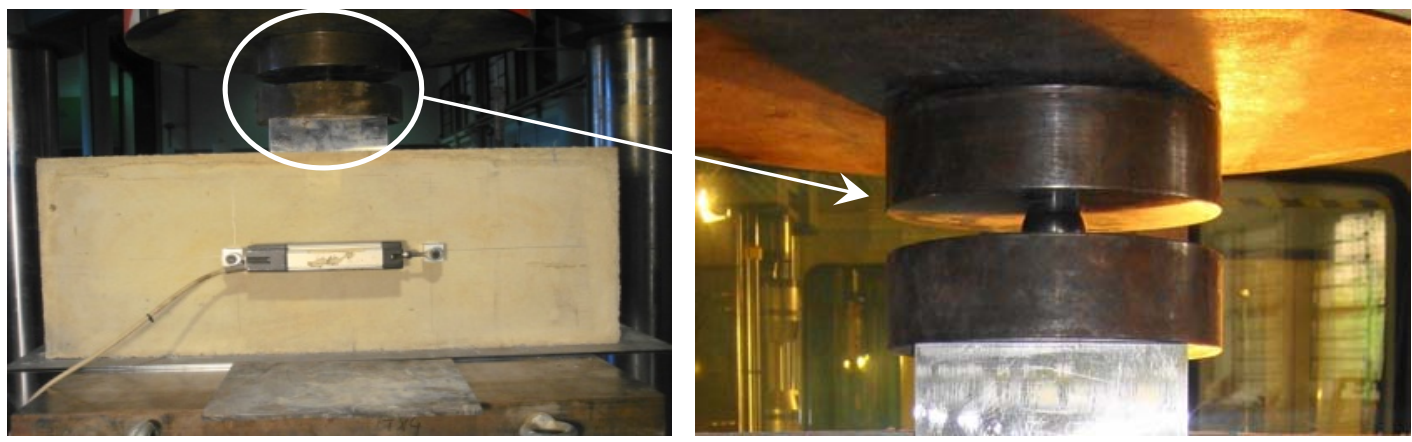

Figure 4. Concentrated load test configuration

Table 3. Test results of the characterization specimens (in $\mathrm{N} / \mathrm{mm}^{2}$ )

\begin{tabular}{|c|c|c|c|c|c|c|}
\hline \multirow{2}{*}{ Series } & \multicolumn{2}{|c|}{ Compression Test } & \multicolumn{2}{c|}{ Barcelona Test } & \multicolumn{2}{c|}{ Brazilian Test } \\
\cline { 2 - 7 } & $\boldsymbol{f}_{c m}$ & $\mathrm{CV}(\%)$ & $\boldsymbol{f}_{c t m 1}$ & $\mathrm{CV}(\%)$ & $\boldsymbol{f}_{\text {ctm2 }}$ & $\mathrm{CV}(\%)$ \\
\hline PC-40 & 43.7 & 1.1 & 4.33 & 1.7 & 4.33 & 2.5 \\
\hline SFRC-40 & 39.4 & 1.9 & 3.99 & 5.4 & 4.74 & 9.2 \\
\hline PC-50 & 53.3 & 0.9 & 4.09 & 5.4 & 4.40 & 5.6 \\
\hline SFRC-50 & 51.8 & 0.9 & 4.32 & 1.9 & 4.49 & 2.4 \\
\hline
\end{tabular}


As expected, the PC specimens presented slightly higher strengths presumably due to the occluded air that the use of fibres leads to in SFRCs. The compressive strengths that were expected based on the materials' compositions were achieved (Table 2). It is worth mentioning that the Barcelona tests presented lower values of the coefficient of variation (CV) than those from the Brazilian tests.

It was observed that most of the blocks cracked in three stages during the concentrated load tests. As shown in Figure 5, in the first stage, a crack is caused due to bursting according to the equilibrium conditions. This is the main crack that progresses through the depth of the specimen as the load increases. In the second stage, diagonal cracks (i.e., secondary cracks with angle $\beta$ ) appear as a result of compatibility demands on the deformed shape; they appear to start at the upper support plate and end at the bottom of the block and are likely caused by spalling stress. Finally, in the third stage, a cone wedge is formed beneath the load transmission plate due to the triaxial compressive stress. This wedge penetrates through the main bursting crack, provoking the physical separation of two semiblocks and decreasing the bearing load. However, the third stage was not always present in plain concrete blocks due to a brittle rupture in the second stage. This is mainly caused by the lack of reinforcement, which reduces internal equilibrium restoring capacity after the first bursting crack occurs.

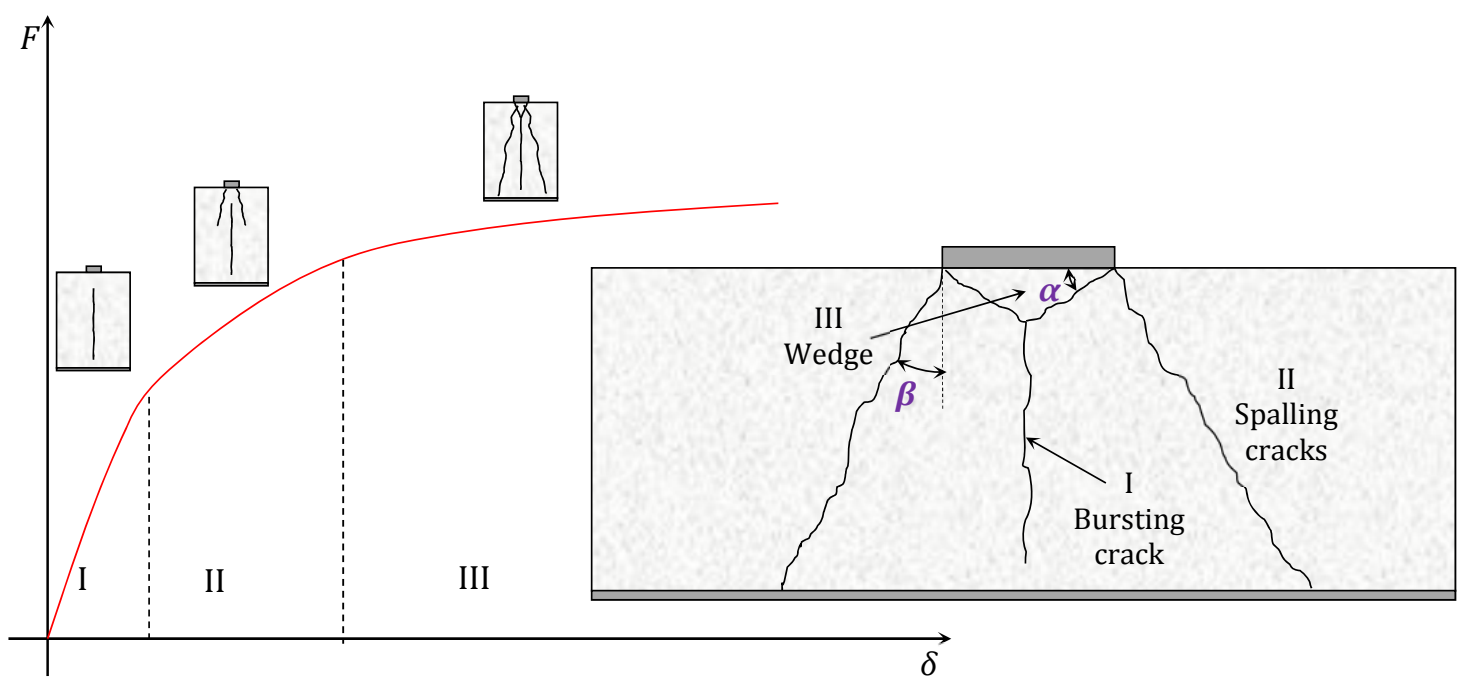

Figure 5. Different crack patterns observed in the tests during the loading process

The load-vertical displacement $(\delta$ ) curves of the concrete blocks grouped by the same block length $\boldsymbol{a}$ are presented in the Figure 6 . The curves correspond to the average values of each series. Similarly, Table 4 shows the results of the first crack load $\left(\boldsymbol{F}_{c r}\right)$ and the maximum load $\left(F_{\max }\right)$. The nomenclature established to refer to the concrete blocks is "Concrete Type- $f_{c}$ $a-a / a_{1}{ }^{\prime \prime}$.

Figs. 6a and 6b and Table 4 show that the series SFRC-40-200-4.0 and SFRC-40-2505.0 (grey-shaded), for which a $50 \times 150 \times 50 \mathrm{~m}^{3}$ steel plate was used instead of the $150 \times 150 \times 50$ $\mathrm{mm}^{3}$ steel plate used for the other series, have a lower load bearing capacity than the series PC-40-200-1.3 and PC-40-250-1.7. Considering that both series present similar tensile concrete strengths (Table 3 ), this effect could be attributed to the ratio $a / a_{1}$ as it has been proven numerically [9] and experimentally [23]. In this regard, the decrease of $a_{1}$ leads to a 
stress concentration above the steel plate and an increase of the bursting stresses.

Conversely, the results also show that the bearing capacity increases with the length of the block and that the load $\boldsymbol{F}_{\max }$ ranges from 2.0 to 3.0 times the load $\boldsymbol{F}_{c r}$. These results reveal the high internal capacity of the system to redistribute stresses by means of both equilibrium and compatibility cracks. These load increases are also observed for both unreinforced and fibre reinforced concrete blocks. The use of $40 \mathrm{~kg} / \mathrm{m}^{3}$ of steel fibres has also been shown to lead to slight differences in $\boldsymbol{F}_{\max }$ with respect to the PC series. However, PC blocks presented only 3 main cracks ( 1 bursting and 2 spalling cracks), as shown in Figure 7a, while SFRC blocks (see Figure $7 \mathrm{~b}$ ) exhibit this same crack pattern with more secondary cracks due to from the higher internal distribution capacity produced by the fibres. This fact is interesting in terms of crack width and service limit state of the precast segments during the TBM jack action.
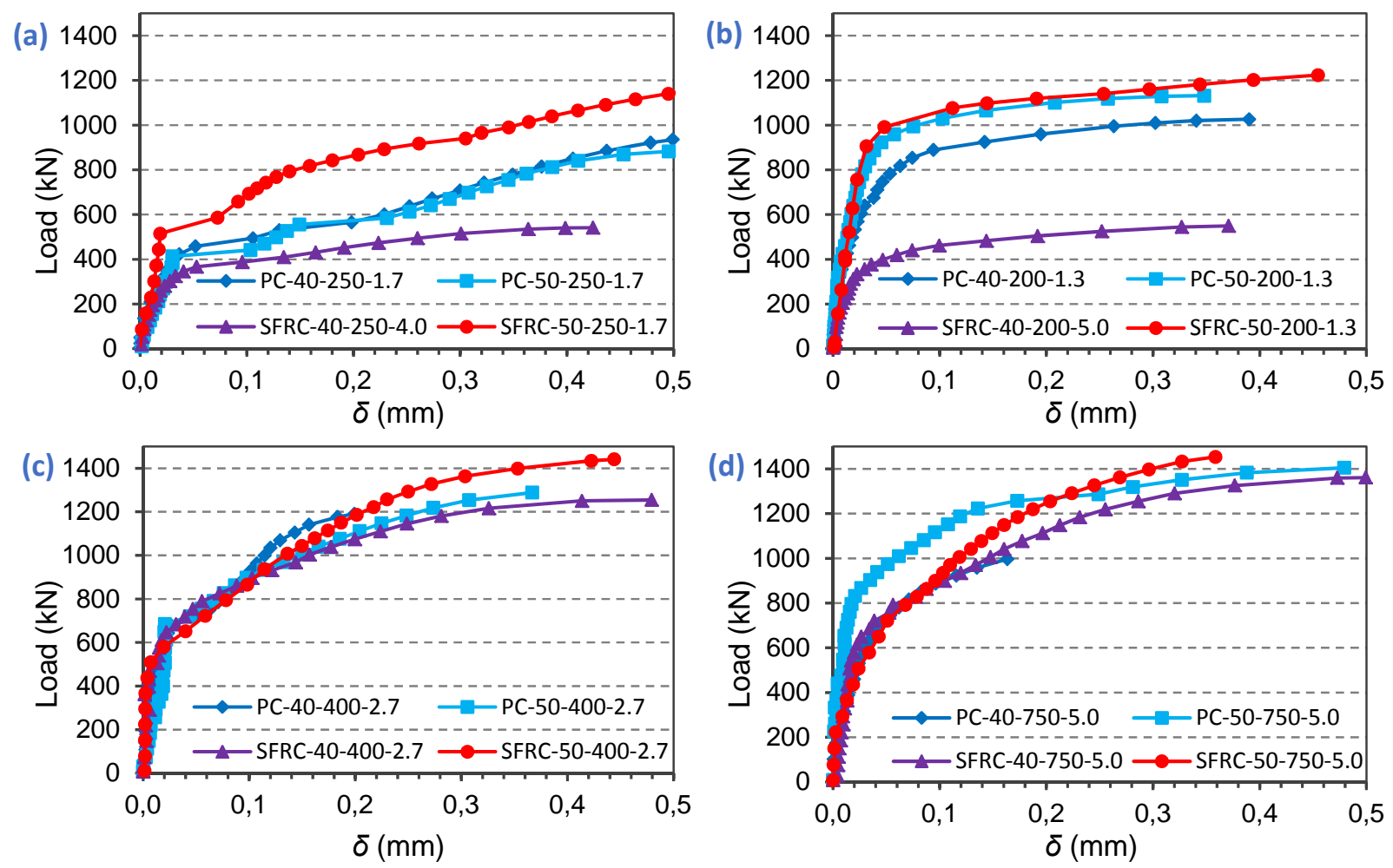

Figure 6. Load - displacement curves of the concrete blocks

Table 4. Experimental loads $\boldsymbol{F}_{\boldsymbol{c r}}$ and $\boldsymbol{F}_{\max }$ measured (in kN)

\begin{tabular}{|c|c|c|c|c|c|c|c|c|c|}
\cline { 3 - 11 } \multicolumn{2}{c|}{} & \multicolumn{8}{c|}{ Length of the block $(a)$} \\
\hline Series & Load & \multicolumn{2}{c|}{$200 \mathrm{~mm}$} & \multicolumn{2}{c|}{$250 \mathrm{~mm}$} & \multicolumn{2}{c|}{$400 \mathrm{~mm}$} & \multicolumn{2}{c|}{$750 \mathrm{~mm}$} \\
\hline \multirow{2}{*}{ PC-40 } & $\boldsymbol{F}_{c r}$ & 401 & 412 & 398 & 421 & 640 & 625 & 708 & 780 \\
\cline { 2 - 12 } & $\boldsymbol{F}_{\max }$ & 1049 & 1038 & 976 & 1081 & 1287 & 1200 & 1340 & - \\
\hline \multirow{2}{*}{ SFRC-40 } & $\boldsymbol{F}_{c r}$ & 396 & 415 & 372 & 376 & 611 & 650 & 672 & 647 \\
\cline { 2 - 11 } & $\boldsymbol{F}_{\max }$ & 536 & 570 & 535 & 571 & 1250 & 1305 & 1299 & 1360 \\
\hline \multirow{2}{*}{ PC-50 } & $\boldsymbol{F}_{c r}$ & 417 & 417 & 416 & 452 & - & - & - & - \\
\cline { 2 - 11 } & $\boldsymbol{F}_{\max }$ & 1166 & 1107 & 1167 & 1108 & - & - & - & - \\
\hline \multirow{2}{*}{ SFRC-50 } & $\boldsymbol{F}_{c r}$ & 435 & 423 & 520 & 533 & 630 & 652 & 712 & 718 \\
\cline { 2 - 10 } & $\boldsymbol{F}_{\max }$ & 1250 & 1150 & 1225 & - & 1485 & 1450 & 1604 & 1459 \\
\hline
\end{tabular}

To calibrate the model presented in this paper, additional measurements of the crack 
patterns were performed. Specifically, the angle $\beta$ of the secondary cracks starting beneath the steel plate were measured in all tested specimens, yielding an average value of $23^{\circ}$ with a CV of $9.2 \%$. Similarly, the dimensions of the cone wedge (see Figure 8 ) formed during the $3^{\text {rd }}$ loading stage (Figure 5) were also measured. It was observed that the height of the cone wedge $(h)$ was approximately equal to the length of the support plate $\left(\boldsymbol{a}_{1}\right)$. The average value of the angle $\alpha$ formed between the upper face of the block and the lateral surface of the cone was $63^{\circ}(\mathrm{CV}=2.2 \%)$.
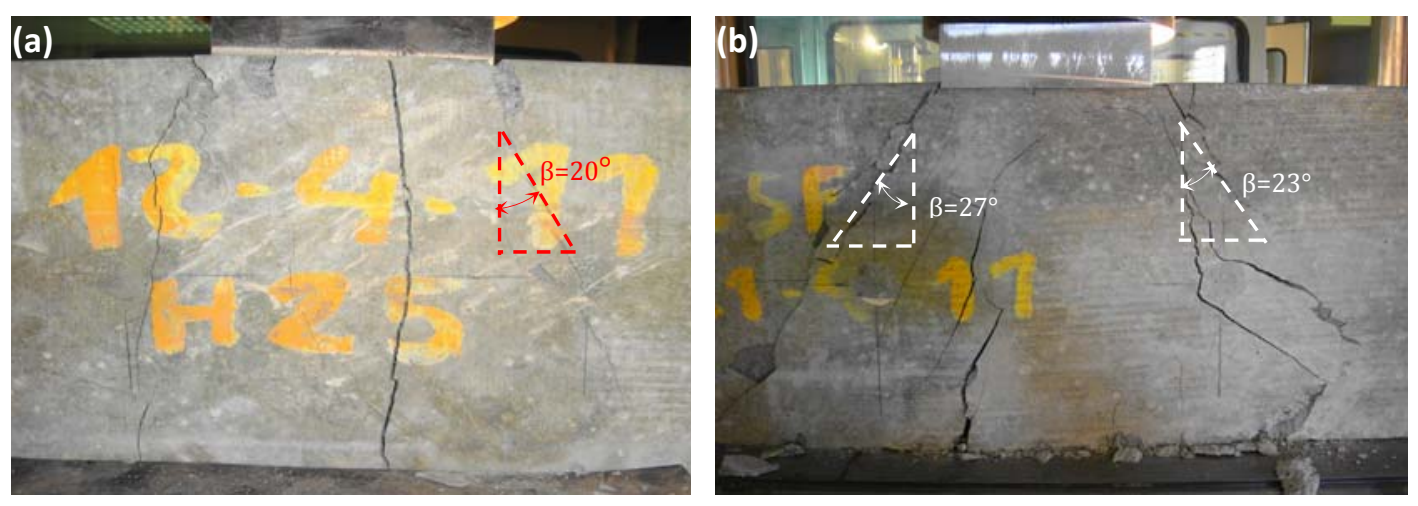

Figure 7. Crack patterns observed in: (a) a PC-40-750 block; and (b) an SFRC-40-750 block
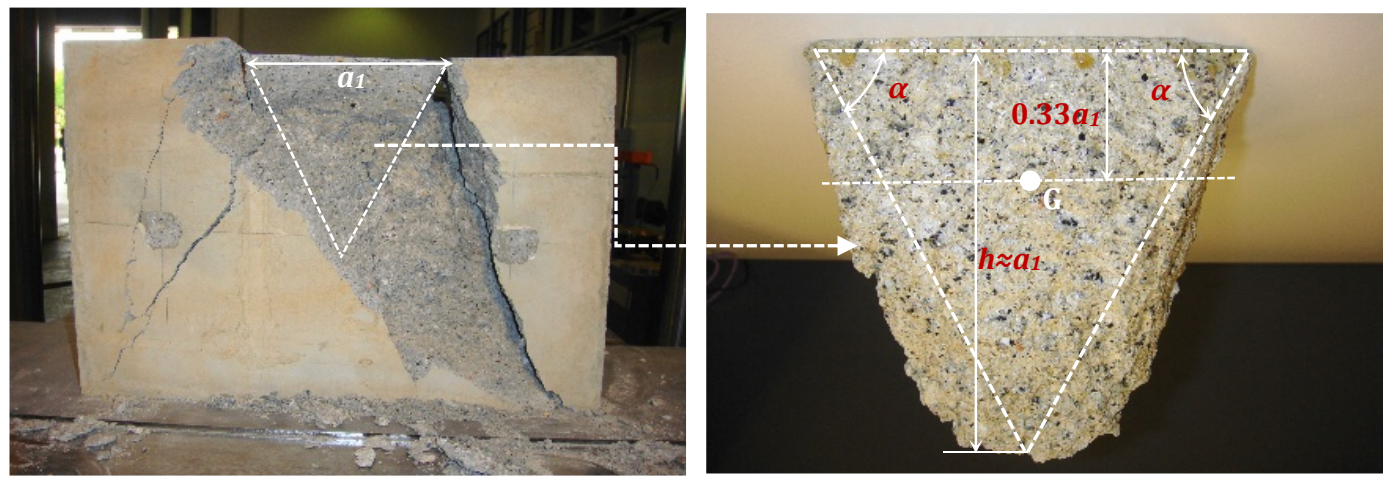

Figure 8. Cone wedge formed during the last loading stage

\section{PROPOSED STRUT AND TIE MODELS TO ASSESS $F_{c r}$ and $F_{\max }$}

\subsection{Introduction}

Based on the analysis of the experimental results previously made, a strut-and-tie model (STM) was adopted to assess the value of the loads $\boldsymbol{F}_{\boldsymbol{c}}$ and $\boldsymbol{F}_{\max }$. These depend on the relationship between the total block height $\left(h_{T}\right)$ and its length $(a)$. Thus, the concrete blocks were divided into two groups: short blocks $\left(\boldsymbol{h}_{T} \geq \boldsymbol{a}\right)$ and long blocks $\left(\boldsymbol{h}_{T}<\boldsymbol{a}\right)$.

In short blocks, $\boldsymbol{F}$ can be distributed along a disturbance length, namely $\boldsymbol{h}$, and reach a uniformly distributed stress pattern $(\sigma)$ within the total length of the block $\boldsymbol{h}_{T}$ [8]; therefore, this stress pattern is also uniform at the support of the block. Conversely, in long blocks, this stress pattern is non-uniform at the base.

According to this classification, the blocks with $a=200$ and $250 \mathrm{~mm}$ belong to the short block group, and those with $a=400$ and $750 \mathrm{~mm}$ belong to the long block group. Therefore, the proposed model was discussed in accordance with these two groups. 


\subsection{Cracking Load $F_{c r}$}

\subsubsection{Short blocks $\boldsymbol{h}_{T} \geq \boldsymbol{a}$}

In the short block series, the STM depicted in Figure 9a was used. This consists of compression members (i.e., struts) and tension members (i.e., ties), which were depicted by dashed and solid line, respectively. Considering the symmetry of the problem, $F$ can be decomposed into loads $F / 2$ acting at a distance $a_{1} / 4$ from the vertical symmetry axis.

Under the loading area, a confined zone was assumed to exist where the compressive stresses are uniform and constant; $\boldsymbol{k}_{1} \boldsymbol{a}_{1}$ was assumed to be the depth of this zone. The $\boldsymbol{k}_{1}$ coefficient can be defined based on experimental results or in accordance with existing regulations. Additionally, $\boldsymbol{h}$, which is also called the fictitious height or disturbance length, represents the required depth that guarantees a uniform distribution of stresses; $h \approx a$ according to Saint - Venant.
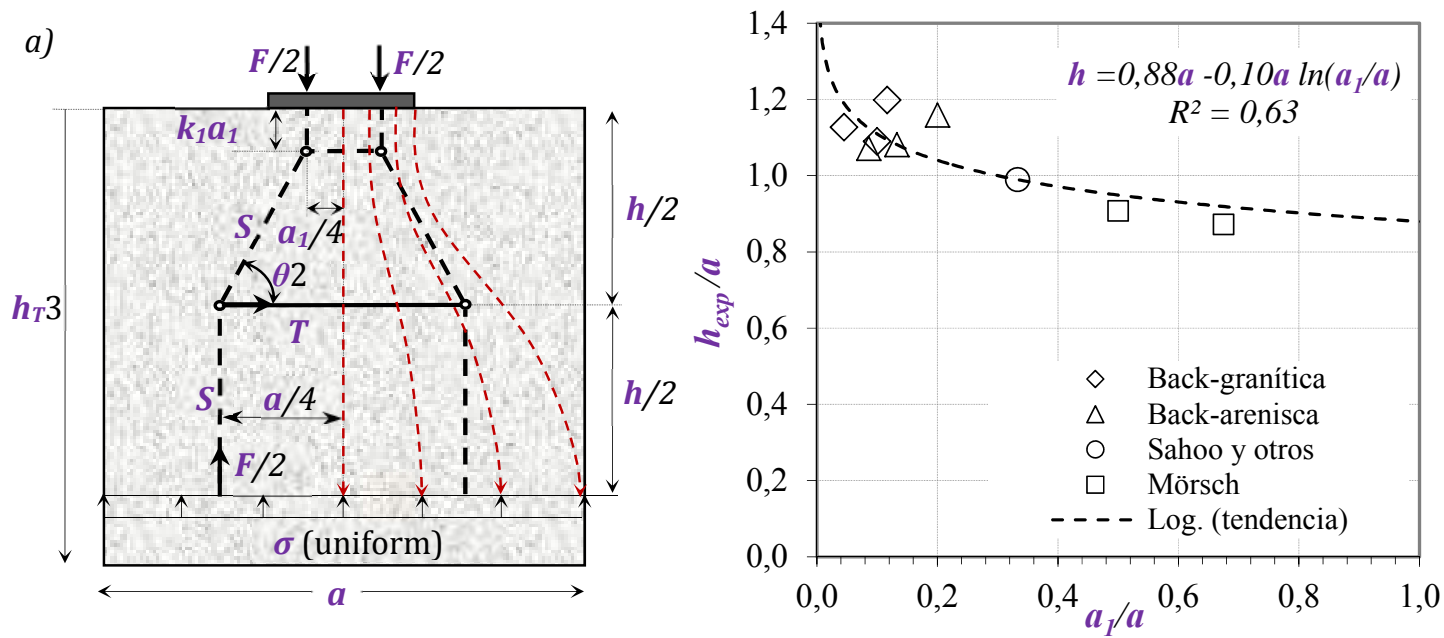

Figure 9. (a) Proposed STM for short blocks; and (b) the determination of $\boldsymbol{h}$

The equilibrium equation resulting from the lattice system presented in Figure 9a results in Eq. (1) that permits the calculation of $T$.

$$
T=\frac{F\left(a-a_{1}\right)}{4\left(h-2 k_{1} a_{1}\right)}
$$

Assuming a parabolic distribution of the tensile stresses acting perpendicularly along the vertical axis and establishing the proper boundary conditions, the maximum tensile stress $\sigma_{c t \text { max }}=3 T / 2 A$ can be derived [44] with $A=b\left(h-k_{1} a_{1}\right)$ being the area subjected to this stress pattern. Thus, from Eq. (1) and $\sigma_{c t, \max }$, Eq. (2) can be obtained.

$$
\sigma_{c t, \max }=\frac{3 T}{2 b\left(h-2 k_{1} a_{1}\right)} \leq f_{c t}
$$

The cracking load $\boldsymbol{F}_{c r}$ can be calculated by combining Eqs. (1) and (2) and letting that $\sigma_{c t m a x}=f_{c t}$, obtaining Eq. (3). 


$$
F_{c r}=\frac{8 b\left(h-2 k_{1} a_{1}\right)\left(h-k_{1} a_{1}\right)}{3\left(a-a_{1}\right)} f_{c t}
$$

For this research project, $\boldsymbol{k}_{1}=0.33$ was adopted because the parametric study of [45] showed that this value is the most representative the triaxial compressive state generated below the loading plate. A function $\boldsymbol{h}=f\left(\boldsymbol{a}, \boldsymbol{a}_{1}\right)$ has also been calibrated from the experimental results presented in [8, 46-47] (Figure 9b). In these studies, different concrete blocks with varying dimensions, concrete strengths and load types were investigated. The values of $\boldsymbol{F}_{c r}$ obtained in these experiments in conjunction with Eq. (3) have been used to calibrate Eq. (4).

$$
h=0.88 a-0.10 a \ln \left(\frac{a_{1}}{a}\right)
$$

Eq. (4) is consistent because for $\boldsymbol{a}_{1} \approx 0$ (i.e., a point load), the disturbance length is infinite while for $\boldsymbol{a}_{1} \approx \boldsymbol{a}$, and the ratio $\boldsymbol{h} / \boldsymbol{a}$ tends to 0.88 . Saint-Venant also proposed $\boldsymbol{h} / \boldsymbol{a} \approx 1$ independently of the loaded area ratio.

\subsection{2. $\quad$ Long blocks $\left(\boldsymbol{h}_{T}<\boldsymbol{a}\right)$}

For long blocks, according to the Saint-Venant principle, the stress pattern at the base of the block is non-uniform (see Figure 10) because $\boldsymbol{h}>\boldsymbol{h}_{T}$. Additionally, it has been observed experimentally that the mechanism can be represented by two blocks: (1) an active block with a length $\boldsymbol{a}_{3}$ compressed within the two cracks inclined at an angle $\beta$, which is responsible the transmission of the external load $F$ transmission; and (2) two lateral blocks that confine the internal active block laterally and contribute to the transfer of the shear stresses either by the aggregate interlock mechanisms or by the action of the fibres.

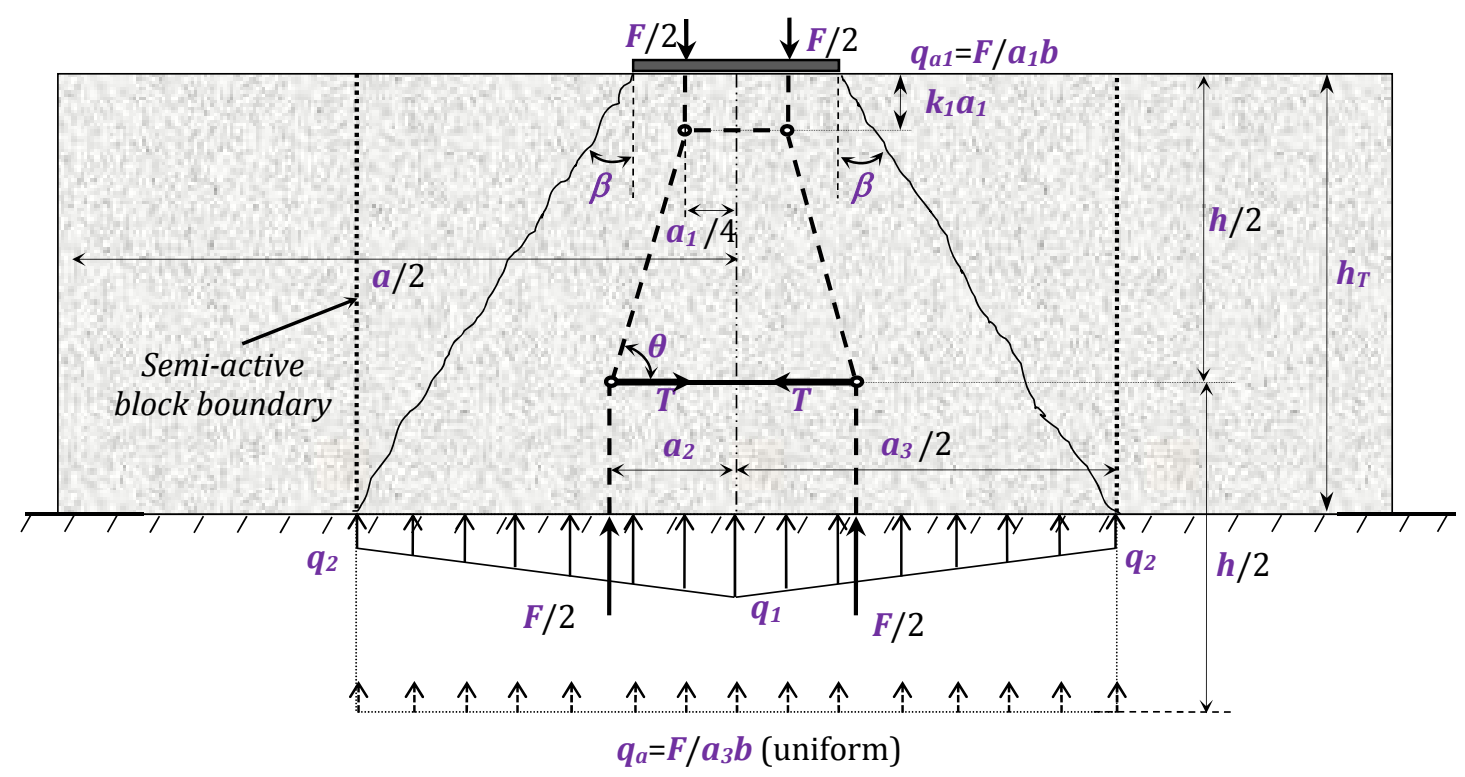

Figure 10. Proposed STM for long blocks

The model proposed assumes that the maximum pressure $q_{1}$ is reached at the intersection of the base with the vertical symmetry axis. This pressure decrease linearly to $q_{1}$ 
at the edge of the active block. This stress distribution results in both $F / 2$ forces, which are located close to the vertical axis; consequently, the internal equilibrium forces reduce its magnitude to $T$ with respect to those forces obtained in short blocks.

Additional hypotheses should be established to determine the magnitude of $T$ : (1) there is a fictitious height $\boldsymbol{h}>\boldsymbol{h}_{T}$ in which the stress $\boldsymbol{q}_{a}=\boldsymbol{F} / \boldsymbol{a}_{3} \boldsymbol{b}$ is uniformly distributed; and (2) the support pressures $q_{1}$ and $q_{2}$ vary between $q_{a 1}=F / a_{1} b$ and $q_{a}$. Assuming these hypotheses, Eqs. (5) and (6) can be derived to assess $q_{1}$ and $q_{2}$, respectively.

$$
\begin{aligned}
& q_{1}=\frac{F}{a_{1} b}\left[1-\frac{h_{T}\left(a_{3}-a_{1}\right)}{a_{3} h}\right] \\
& q_{2}=\frac{2 F}{a_{3} b}-q_{1}
\end{aligned}
$$

To obtain $q_{2}<0$ in Eq. (6), the stress distribution can be assumed to be triangular; thus, the pressures become $q_{2}=0$ and $q_{1}=2 F / a_{3} b$ and $\boldsymbol{a}_{2}=\boldsymbol{a}_{3} / 6$. Furthermore, by applying geometrical considerations, the restriction expressed by Eq. (7) can be established.

$$
a_{3}=a_{1}+2 h_{T} \tan \beta \leq a
$$

By imposing the resulting force from the non-uniform pressure pattern equal to $F / 2$, Eq. (8) can be obtained. This allows the calculation of $\boldsymbol{a}_{2}$.

$$
a_{2}=\frac{a_{3}}{6}\left(\frac{q_{1}+2 q_{2}}{q_{1}+q_{2}}\right)
$$

Following the same criteria established to derive Eqs. (1-3) for short blocks, Eq. (9) can be deduced to obtain the value of $\boldsymbol{F}_{c r}$ for long blocks.

$$
F_{c r}=\frac{8 b\left(h-2 k_{1} a_{1}\right)\left(h-k_{1} a_{1}\right)}{3\left(4 a_{2}-a_{1}\right)} f_{c t}
$$

Using the experimental values of $\boldsymbol{F}_{c r}$ for long blocks in [2], the calibrated Eq. (10) can be used to assess the value of $\boldsymbol{h}$.

$$
h=0.71 a-0.22 a_{3} \ln \left(\frac{a_{3}}{a}\right)
$$

\subsection{Maximum load $F_{\max }$}

It has been observed experimentally that the blocks were divided into two main sections after cracking (Figure 11). This causes a drastic change in the internal stress distribution that is difficult to assess analytically. In such a situation, the two parts are subjected to loads with an eccentricity $k_{2} a$, which leads to a flexural-compression state in each independent part. 

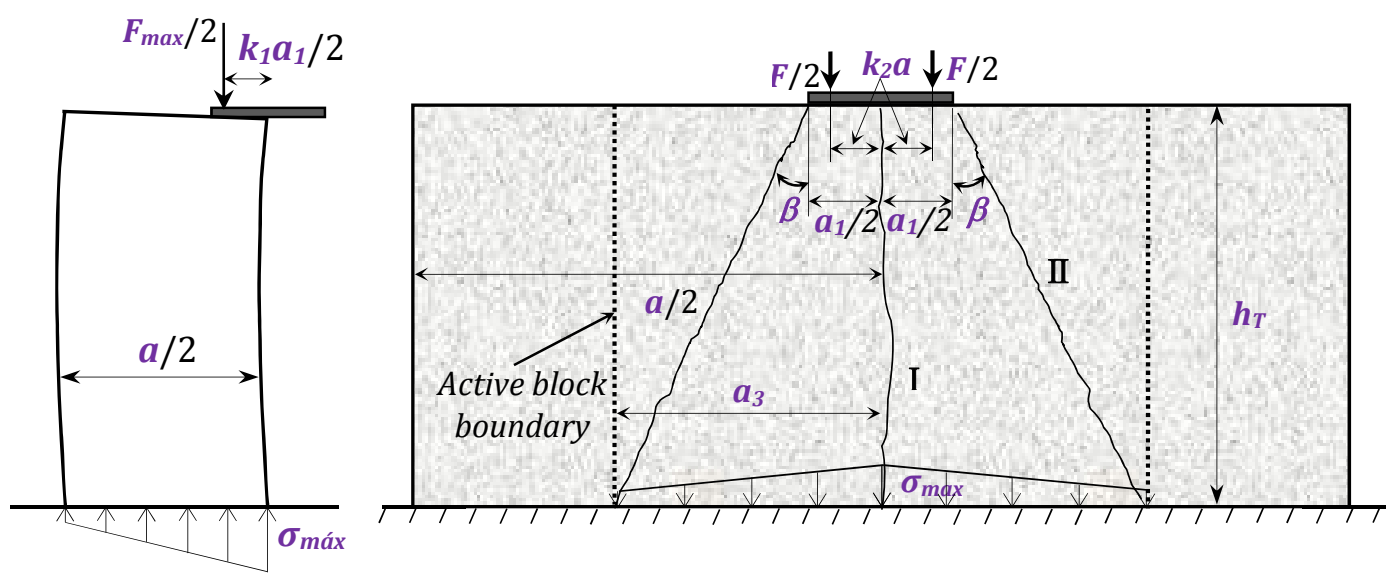

Figure 11. Theoretical scheme of the fissure formed during the block test

By imposing the classical formula of mechanics of the materials, the maximum compressive stress $\sigma_{c c, \max }$ acting at the central part of the block can be assessed (Eq. (11)).

$$
\sigma_{c, \text { max }}=\frac{F_{\max } / 2}{b a_{3} / 2}+\frac{F_{\max } / 2\left(a_{3} / 4-k_{2} a_{1} / 2\right)}{b\left(a_{3} / 2\right)^{3} / 12} \frac{a_{3}}{4}=\frac{F_{\max }}{b a_{3}{ }^{2}}\left(4 a_{3}-6 k_{2} a_{1}\right)
$$

Assuming that the failure of the block is reached when the maximum compressive stress equals the compressive strength of the concrete $\left(\sigma_{c c, \max }=f_{c}\right)$, the value of $\boldsymbol{F}_{\max }$ can be derived from Eq. (11) obtaining Eq. (12).

$$
F_{\text {max }}=\frac{b a_{3}^{2}}{4 a_{3}-6 k_{2} a_{1}} f_{c}
$$

It should be highlighted that $\boldsymbol{F}_{\max }$ depends on the geometric variables $\left(\boldsymbol{b}, \boldsymbol{a}_{1}\right.$ and $\left.\boldsymbol{a}_{3}\right)$, the concrete compressive strength $f_{c}$ and the eccentricity factor $k_{2}$ of the load in the failure regime. It is also important to note that the contribution of the fibres is not taken into account in the failure state because of their minimal impact, as shown in Table 4 by comparing the values of $\boldsymbol{F}_{\max }$ for PC and SFRC blocks. With larger amounts of fibres, the failure mechanism might change, and the contribution of the fibres should be considered in the analysis; otherwise, the value of $\boldsymbol{F}_{\max }$ assessed would be underestimated. Additionally, the precast segments are designed so that the cracking is not allowed during the placing operations.

In Eq. (12), $\boldsymbol{a}_{3}$ can be determined by Eq. (7); $\boldsymbol{k}_{2}$ should be derived from Eq. (13) (Figure 12), which has been calibrated with the experimental values of $\boldsymbol{F}_{\max }$ presented in [8] and considering Eq. (12):

$$
k_{2}=e^{-0.70 \frac{a_{1}}{a_{3}}}
$$

Eq. (13) is shown to be consistent with the physical phenomena: for a point load ( $\boldsymbol{a}_{1} \approx$ 0 ), the ratio $a_{1} / a_{3} \approx 0$, and consequently, $k_{2} \approx 1.0$, meaning that the load $F / 2$ is applied at the internal edge of the plate in the failure regime. Contrarily, if $a_{1}=a_{3}\left(a_{1} / a_{3}=1.0\right)$, then $k_{2}$ tends towards 0.5 , and therefore, $F / 2$ is applied at a distance $a_{1} / 4$ from the vertical axis of the block, which coincides with the central point of the symmetry axis of the loading semi-plate. 


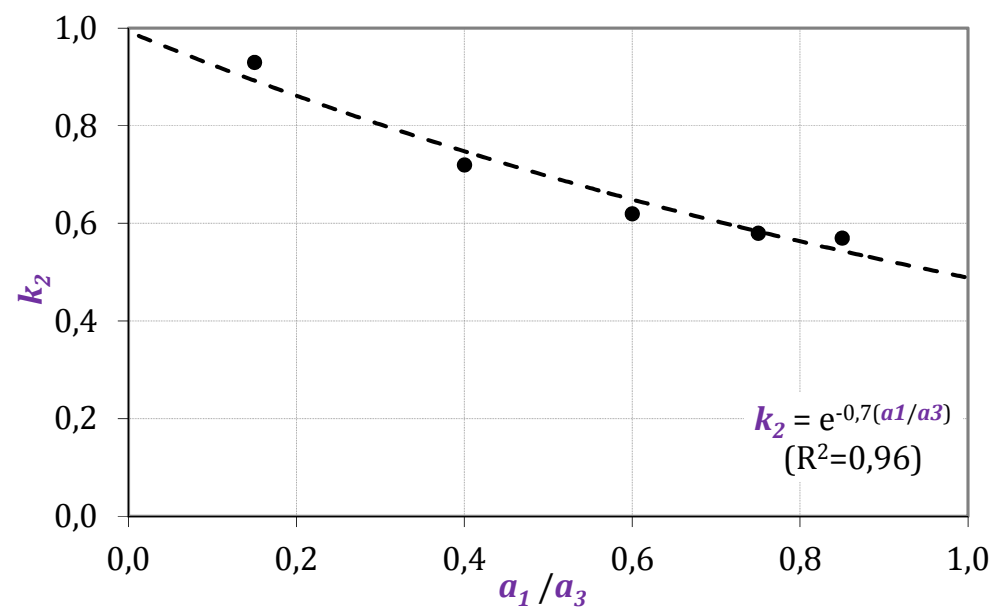

Figure 12. Values of $\boldsymbol{k}_{2}$ derived from the experimental values of $\boldsymbol{F}_{\max }$ presented in [2]

\subsection{Comparing the experimental and theoretical values of $F_{c r}$ and $F_{\max }$}

Tables 5 and $\mathbf{6}$ present both the experimental results and the theoretical values of $\boldsymbol{F}_{c r}$ and $\boldsymbol{F}_{\max }$ estimated using Eqs. (3) and (9) for $\boldsymbol{F}_{\boldsymbol{c r}}$ and Eq. (12) for $\boldsymbol{F}_{\max }$.

Table 5. Comparison between theoretical and experimental average values for $\boldsymbol{F}_{c r}$ (relative error in \%)

\begin{tabular}{ccc|ccc}
\hline Specimen & Exp. & Th. & Specimen & Exp. & Th. \\
\hline PC-40-200-1.3 & 407 & $379(6.9)$ & PC-50-200-1.3 & 417 & $358(14.1)$ \\
PC-40-250-1.7 & 409 & $425(-3.9)$ & PC-50-250-1.7 & 434 & $401(7.6)$ \\
PC-40-400-2.7 & 633 & $725(-14.5)$ & PC-50-400-2.7 & - & - \\
PC-40-750-5.0 & 744 & $750(-0.8)$ & PC-50-750-5.0 & - & - \\
SFRC-40-200-5.0 & 406 & $340(16.3)$ & SFRC-50-200-1.3 & 429 & $378(11.9)$ \\
SFRC-40-250-4.0 & 374 & $441(-17.9)$ & SFRC-50-250-1.7 & 527 & $424(19.5)$ \\
SFRC-40-400-2.7 & 631 & $668(-5.9)$ & SFRC-50-400-2.7 & 641 & $724(-12.9)$ \\
SFRC-40-750-5.0 & 660 & $691(-4.7)$ & SFRC-50-750-5.0 & 715 & $748(-4.6)$ \\
\hline
\end{tabular}

Table 6. Comparison between theoretical and average experimental values for $\boldsymbol{F}_{\max }$ (relative error in \%)

\begin{tabular}{ccc|ccc}
\hline Specimen & Exp. & Th. & Specimen & Exp. & Th. \\
\hline PC-40-200-1.3 & 1044 & $980(6.1)$ & PC-50-200-1.3 & 1137 & $1195(5.1)$ \\
PC-40-250-1.7 & 1029 & $1003(2.5)$ & PC-50-250-1.7 & 1138 & $1223(7.5)$ \\
PC-40-400-2.7 & 1244 & $1156(7.1)$ & PC-50-400-2.7 & - & - \\
PC-40-750-5.0 & 1340 & $1162(13.3)$ & PC-50-750-5.0 & - & - \\
SFRC-40-200-5.0 & 553 & $431(22.1)$ & SFRC-50-200-1.3 & 1200 & $1161(3.3)$ \\
SFRC-40-250-4.0 & 553 & $500(9.6)$ & SFRC-50-250-1.7 & 1225 & $1187(3.1)$ \\
SFRC-40-400-2.7 & 1278 & $1041(18.5)$ & SFRC-50-400-2.7 & 1468 & $1368(6.8)$ \\
SFRC-40-750-5.0 & 1330 & $1047(21.3)$ & SFRC-50-750-5.0 & 1532 & $1375(10.2)$ \\
\hline
\end{tabular}

The results presented in the Table 5 highlight the suitability of the analytical model proposed to assess $F_{c r}$ of both short and long blocks. The STM leads to a maximum underestimation for $\boldsymbol{F}_{c r}$ of $16.3 \%$ (SFRC-40-200-5.0) with respect to the experimental value; conversely, maximum overestimation of $-17.9 \%$ (SFRC-40-250-4.0) is also calculated. The 
absolute average relative error of $\boldsymbol{F}_{c r}$ was calculated to be $10.1 \%$. Considering these results, it can be assumed that these are satisfactory in terms of design because, although there is a certain deviation of the proposed model, these errors are limited and lower than those inherent errors accepted for the materials' strengths. Despite being an SLS, safety factors for $F_{c r}$ applied during the design procedure usually exceed 1.5.

It can be confirmed from the results of Table 6 that the agreement between the experimental and theoretic results of obtained with the proposed STM are even better with respect to those of $\boldsymbol{F}_{c r}$. The maximum and minimum relative errors are $22.1 \%$ (SFRC-40-2005.0 ) and $2.5 \%$ (PC-40-250-1.7), respectively, and the average is 9.8\%. Therefore, taking into account the aforementioned for $\boldsymbol{F}_{c r}$, these results also highlight the suitability of the analytical model to assess the value of $\boldsymbol{F}_{\max }$. The assessment of load is thus not relevant to the calculation of $F_{c r}$ in the design of precast concrete segments.

\section{APPLICATION TO LINE 9 IN BARCELONA}

Because the formulations that estimate the cracking and ultimate loads have been proposed, an application is now considered regarding the segmented lining in Metro Line 9 in Barcelona. The tunnel is constructed with an EPB TBM that excavates an external diameter of $11890 \mathrm{~mm}$. The reinforced concrete ring installed has an internal diameter of $10900 \mathrm{~mm}$, a thickness of $350 \mathrm{~mm}$ and an average width of $1800 \mathrm{~mm}$. As shown in Figure 13, the TBM is composed by 7 segments and a key. The ratio between the thickness and the diameter of the ring is approximately 31, whereas most tunnels have the same parameter between 20 and 25 . The high slenderness of the ring from the Metro Line 9 in Barcelona in comparison with other tunnels may lead to the application of higher stress levels to the segment. Together with the possible eccentricity of the jacks, this might increase the risk of bursting cracks.
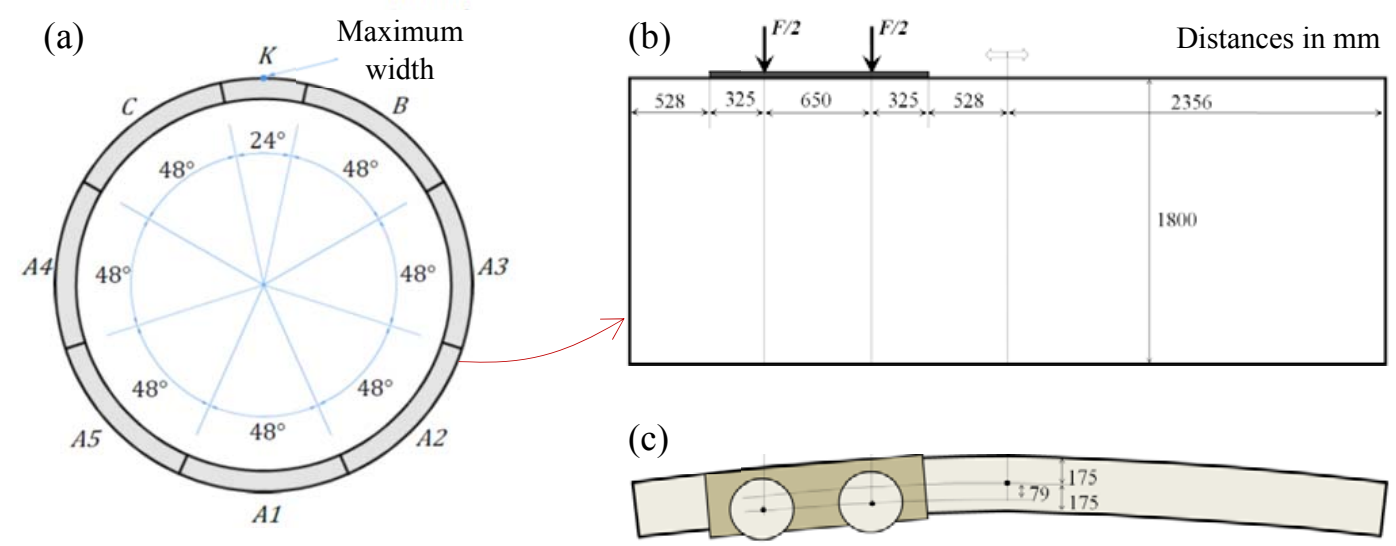

Figure 13. Detail of ring (a), front (b) and top view (c) of load application in the segment

During the construction process, the load required to generate enough pressure to excavate the front face and to advance the TBM is generated by 15 pairs of thrust jacks. Each pair transmits the forces to a $20 \mathrm{~mm}$ thick steel plate, known as a pad. The pads transmit this force to the recently installed ring that acts like a reaction frame. Segments A1, A2, A3, A4, A5, $B$ and $C$ receive the load from two pads, whereas the key segment receives the load from only one pad. Figures $13 \mathrm{~b}$ and $13 \mathrm{c}$ depict a front view and a top view of the load application 
points.

Notice that a design eccentricity of $79 \mathrm{~mm}$ towards the centre of the ring is already considered in the project (Figure 13c). Such eccentricity is intentionally used to generate compressive forces in the longitudinal joints, thus reducing the risk of collapse when the segments are still inside the TBM, and only a small compression exists. The magnitude of the load applied by the thrust jacks during the construction process will depend on the properties of the ground excavated, the position of the segment inside the ring, and the curvature of the stretch, among other factors. In [47], there is an extensive study of the variability of the forces applied in Line 9 in Barcelona. The results suggest that the average load during construction is $2600 \mathrm{kN} / \mathrm{pad}$. However, in [48], the maximum load is found to be approximately $4660 \mathrm{kN} / \mathrm{pad}$. The latter is taken as a reference for the calculations performed here.

Depending on the magnitude of the load and the support conditions of the segments, different types of damage could occur in the segments during construction. According with the study performed by the Japanese Society of Civil Engineers, most damage is associated with the handling of the segments and with the application of the thrust forces when the segments are leaving the shield [49]. Although not the most frequent type, one of the possible types of damage that might occur in this last situation is depicted in Figure 14.

Figure 14 shows only half of the top view of the segment from Line 9 in Barcelona with a crack parallel to the width that starts closer to the point of application of the load from the thrust jacks. The mechanism of crack formation in this case is similar to that described in Sections 3 and 4 of this study. Due to the dimensions of the segment and the reduced area of the pads, the segment behaves like a block subjected to concentrated loads. In fact, these loads produce tensile stresses that might crack and even produce a failure of the segments. Notice that even if the support provided by the previous ring installed was perfect, failure might still take place.

The formulation developed here might be used to predict the safety factor (SF) in service and in ultimate limit states related with this type of damage. To perform this estimation following the project specifications, it is assumed that a segment should not crack in service. Additionally, the characteristic compressive $\left(f_{c}\right)$ and tensile $\left(f_{c t}\right)$ strengths of concrete are $50 \mathrm{~N} / \mathrm{mm}^{2}$ and $2.7 \mathrm{~N} / \mathrm{mm}^{2}$, respectively. The height of the segment $\boldsymbol{h}_{T}$ is 1800 $\mathrm{mm}$, the length of the load application $\boldsymbol{a}_{1}$ equals that of the pad (i.e., $1300 \mathrm{~mm}$ ), the eccentricity of forces $a_{2}$ is $574 \mathrm{~mm}$, the length of the segment $(a)$ considering the symmetry axis is $2356 \mathrm{~mm}$, the coefficient $\boldsymbol{k}_{1}$ that determines the length of the confined zone is 0.3 and the depth below which internal stresses become uniform $(h)$ is $1981 \mathrm{~mm}$.

Because $\boldsymbol{h}_{T}$ is smaller than $\boldsymbol{a}$, Eq. (9) is used to estimate a cracking load $\boldsymbol{F}_{c r}$ of $7161 \mathrm{kN}$. Conversely, Eq. (12) is used to assess the maximum load $\boldsymbol{F}_{\max }$, which is $23559 \mathrm{kN}$. The SF in a service-limit state (SLS) is obtained by dividing $F_{c r}$ by the maximum load per pad. This gives an SF of 1.54. The same is performed for the ultimate limit state (ULS) using $\boldsymbol{F}_{\max }$. As a result, an SF of 5.06 is obtained. 


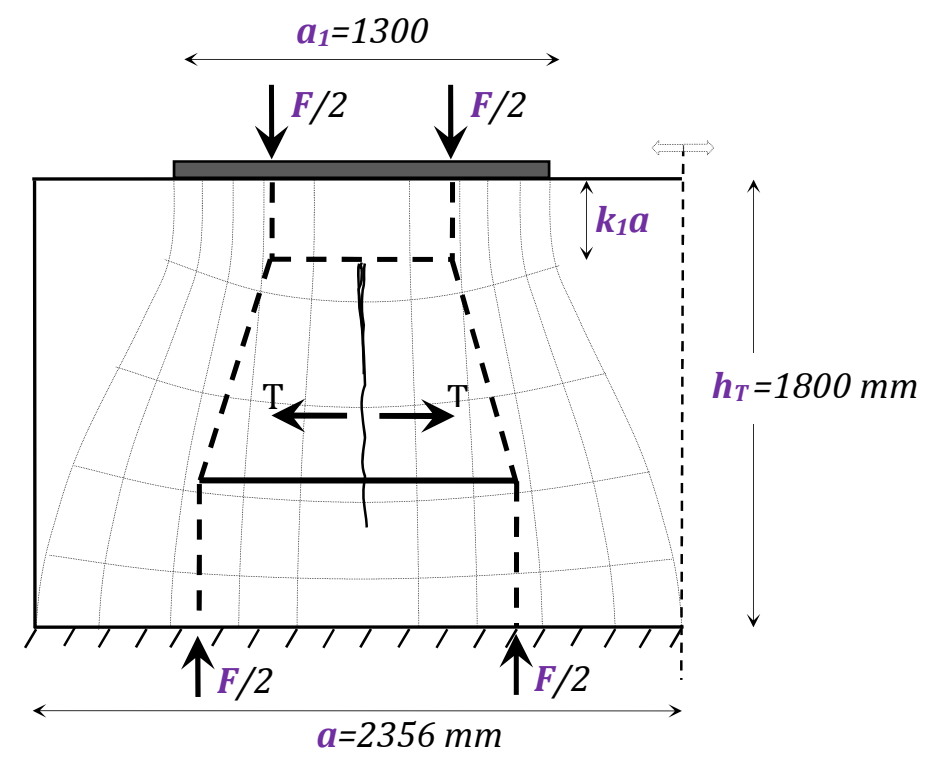

Figure 14. Symmetric top view of a segment from Line 9 in Barcelona with a crack

Following [50], an SF of 2.0 is recommended to avoid the use of any reinforcement. Although smaller values are obtained in SLS, it is important to consider that the typical SF in service is assumed to be 1.0 and that more than enough safety margin remains regarding the ULS. It is also necessary to consider that the maximum load from the thrust jacks were used in the calculation and that a low risk of collapse is associated with this type of cracking once the ring leaves the shield. Based on these considerations, it is possible justify that no reinforcement is required; however, a combination of reinforcing bars and steel fibres were used in these precast segments due to the relatively high bending moments expected in some lengths of the tunnel.

An extensive experimental program was performed in the Metro Line 9 in Barcelona to evaluate the possibility of replacing the traditional reinforced concrete segment by a fibrereinforced concrete equivalent [47]. During the experimental program, 30 rings reinforced solely with steel fibres were installed in a curved stretch. The inspection of these segments showed that no longitudinal cracks occurred due to bursting stresses. This is consistent with the results obtained through the application of the analytical model.

\section{Conclusions}

An experimental investigation was performed to study the mechanical behaviour of concrete blocks with different dimensions with and without steel fibres under concentrated loads. Through the study, three simplified analytical formulations based on STM were proposed. To fully understand the proposed model, a case study at Metro Line 9 in Barcelona was discussed.

The main conclusions of this study are described below:

- $\quad$ As a simple and accurate method for structural analysis, the strut-and-tie model shows a reliable ability to analyse concentrated loads on concrete blocks. The depth of the confined area of the blocks significantly affects the form of the proposed formulations to predict the mechanical behaviour of the concrete blocks. 
- In blocks with greater length than height, only a portion of the blocks is responsible for transmitting the applied loads. The area that effectively contributes to the transmission of stress is defined by an angle equal to $23^{\circ}$, according to experimental results.

- $\quad$ From the comparisons of theoretical and experimental values of $\boldsymbol{F}_{\text {fis }}$ and $\boldsymbol{F}_{\text {rup }}$, it has been verified that the formulations proposed could predict the mechanical behaviour of the blocks in the experimental study.

- Due to its simplicity and accuracy, the formulations developed in this work could serve as a basis for predicting the mechanical behaviour of concrete blocks subjected to concentrated loads.

- $\quad$ The application of the formulations developed for Line 9 in Barcelona indicates that a safety factor of 1.51 and 5.06 exist in the SLS and the ULS, respectively. These results suggest that no specific reinforcement should be placed to resist the tensile forces that arise due to the concentrated loads applied by the thrust jack pads.

\section{Acknowledgements}

The authors want to thank the Ministry of Science and Innovation for the economic support received through Research Project BIA2010-17478: Construction processes by means of fibre reinforced concretes. The first author would like to acknowledge the scholarship received from the China Scholarship Council.

\section{References}

1. Waal, R.G.A. de. 1999. "Steel fibre reinforced tunnel segments", Delft, ISBN 90-407-1965-9, Delft University of Technology.

2. Cavalaro, S H P, Blom, C B M, Walraven, J C, Aguado, A.. Structural analysis of contact deficiencies in segmented lining. Tunnelling and Underground Space Technology 2011. 26 (6): 734-749

3. Cavalaro, S H P, Blom, C B M, Aguado, A, Walraven, J C. New Design Method for the Production Tolerances of Concrete Tunnel Segments.

4. Cavalaro, S H P, Blom, C B M, Walraven, J C, Aguado, A. Formation and accumulation of contact deficiencies in a tunnel segmented lining. Applied Mathematical Modelling 2012. 36 (9):4422-4438

5. Walraven, J., 2009. High performance fibre reinforced concrete: progress in knowledge and design codes. RILEM Materials Structures 42 (9), 1247-1260.

6. de la Fuente, A., Pujadas, P., Blanco, A., Aguado, A., 2011. Experiences in Barcelona with the use of fibres in segmental linings. Tunneling and Underground Space Technology 27 (2012) 60-71.

7. Ritter, W. (1899). Die Bauweise Hennebique (Construction Techniques of Hennebique). Schweizerische Bauseitung. Zurich, February. 
8. Mörsch, Emil (1902). Der Eisenbetonbau, seine Theorie und Anwendung (Reinforced Concrete, Theory and Apllication). Stuggart. Germany.

9. Leonhardt, F. (1965). Über die Kunst des Bewehrens von Stahlbetontragwerken. Betonund Stahlbetonbau 60, H.8, pp. 181; H.9, pp. 212.

10. Iyengar, K.T.S.R.; Yogananda, C.V. (1966). A three dimensional stress distribution problem in the end zones of pre-stressed beams. Magazine of Concrete Research, 18, 75.84 .

11. Kooiman, A.G., 2000. Modelling steel fibre reinforced concrete for structural design. Ph.D. thesis, Delft University of Technology.

12. Blom C.B.M. 2002. "Design philosophy of concrete linings in soft soils", ISBN 90-4072366-4, Delft University of Technology.

13. Hemmy O. 2001. Brite Euram Program on Steel Fibre Concrete, Subtask: Splitting of SFRC induced by local forces, "Investigation of tunnel segments without curvature", University of Braunschweig (Germany).

14. Schnüntger g., Erdem E. 2001. Brite Euram Program on Steel Fibre Concrete, Subtask: Splitting of SFRC induced by local forces, Ruhr-University, Bochum (Germany).

15. Gettu, R., Barragán, B., García, T., Ramos, G., Fernández, C., and Oliver, R., 2004. "Steel Fiber Reinforced Concrete for the Barcelona Metro Line 9 Tunnel Lining." In BEFIB 2004, Proc of the $6^{\text {th }}$ RILEM Symposium on FRC, Varenna (Italy), September 20-22, RILEM PRO 39, pp. 141-156.

16. Sorelli L., Toutlemonde F. On the design of steel fiber reinforced concrete tunnel lining segments. 11th International Conference on Fracture, Turin (Italy), March 20-25, 2005. Extended Abstract

17. de Rivaz B. 2008. Steel fibre reinforced concrete (SFRC): The use of SFRC in precast segment for tunnel lining. In: World Tunnel Congress ITA-AITES 2008, Agra, India, September 22-24, pp. 2007-2017.

18. Pohn J., Tan KH, Peterson GL., Wen D: Structural testing of steel fibre reinforced concrete (SFRC) tunnel lining segments in Singapore, WTC 2009, Budapest, Hungary

19. Caratelli, A., Meda, A., Rinaldi, Z., Romualdi, P. Structural behaviour of precast tunnel segments in fiber reinforced concrete. Tunnelling and Underground Space Technology 2011, 26(2):284-291

20. Caratelli, A., Meda, A., Rinaldi, Z. Design according to MC2010 of fibre-reinforced concrete tunnel in Monte Lirio, Panama. Structural Concrete 2012, 13(3): 166-173

21. Hilar M., Vítek P. Experimental loading tests of steel fibre reinforced and traditionally reinforced precast concrete segments for tunnel linings. Tunnelling and Underground Space Technology2012. 21(4): 54-65. 
22. Beno J., Hilar M. Steel fibre reinforced concrete for tunnel lining - verification by extensive laboratory testing and numerical modelling. Acta Polytechnia 53(4):329-337, 2013.

23. Breitenbücher R., Meschke G., Song F., Hofman M., Zhan Y. Experimental and numerical study on the load-bearing behavior of steel fiber reinforced concrete for precast tunnel lining segments under concentrated loads. FRC 2014 Joint ACI-fib International Workshop. Fibre Reinforced Concrete Applications. 24-25 July 2014, Montreal, Canada. pp. 417 - 429.

24. Abbas S., Soliman A., Nehdi M. Structural behaviour of ultra-high performance fibre reinforced concrete tunnel lining segments. FRC 2014 Joint ACI-fib International Workshop. Fibre Reinforced Concrete Applications. 24-25 July 2014, Montreal, Canada. pp. 532 - 543.

25. ABAQUS/STANDARD, User's Manual, Hibbitt, Karlsson \& Sorensen, Inc., Pawtucket. 1995

26. Ansys Rev. 5.5, User Manual, Swanson Analysis Systems, Houston

27. Cervenka V., Jendele L., Cervenka J. ATENA Program documentation. Prague, Czeck Republic, 2013. Cervenka Consulting s.r.o.

28. Marc User's Guide, U.S. A, 2008.

29. Burgers, R., Walraven, J.C., Plizzari, G.A., Tiberti G., 2007. Structural Behaviour of SFRC Tunnel Segments during TBM Operations. Underground Space the 4th Dimension of Metropolises: Proceedings of the World Tunnel Congress 2007 and 33rd ITA/AITES Annual General Assembly, London, England, pp. 1461-1467.

30. Tiberti G., Plizzari G. Structural behaviour of precast tunnel segments under TBM thrust actions. World Tunnelling Congress: Tunnels for a Better Life (WTC 2014), 9 - 15 of May 2014, Foz do Iguaçu, Brazil. ISBN 978-85-67950-00-6. Text in CD of Proceedings.

31. Ramirez, J. A., and Breen, J. E., 1991, "Evaluation of a Modified Truss-Model Approach for Beams in Shear," ACI Structural Journal, V. 88, No. 5, Sept.-Oct., pp. 562-571.

32. Reineck, K.-H., 1982, "Models for the Design of Reinforced and Prestressed Concrete Members," CEB Bulletin 146, Paris, pp. 43-96.

33. ACI-ASCE Committee 445, 2000, Recent Approaches to Shear Design of Structural Concrete, pp. 445R, 38-47.

34. Toutlemonde, F., 'Analyse des résultats des essais de voussoirs de tunnel par des méthodes de dimensionnement approchées'. 2000, National Project BEFIM, report, LCPC.

35. Toutlemonde F., Quiertant M., Dubroca S. Justification du reinforcement des voussoirs prefabriques de tunnels: Expérimentations sur voissoirs en béton armé et béton de fibres. Tunnels et ouvrages souterrains, n. 162, Nov/Dec 2000.

36. Haring, F.P., Stresses in assembly phase and serviceability phase in the lining of shield driven tunnels- Delft University of Technology, The Netherlands, 2002. 
37. Groeneweg TW. Shield driven in ultra-high strength concrete: reduction of the tunnel lining thickness. Minor Thesis, Delft University of Technology. 2007.

38. Bakhshi M., Nasri V. Developments in design for fiber reinforced concrete tunnel segments. FRC 2014 Joint ACI-fib International Workshop. Fibre Reinforced Concrete Applications. 24-25 July 2014, Montreal, Canada. pp. 441 - 452.

39. UNE-EN 12390-3 (2011). Testing hardened concrete - Part 3: Compressive strength of test specimens. Compression test. Spanish Association for Standardization and Certification, AENOR.

40. UNE-EN 12390-6 (2010). Testing hardened concrete - Part 6: Tensile splitting strength of test specimens. Brazilian test. Spanish Association for Standardization and Certification, AENOR.

41. UNE 83515 (2010). Fibre reinforced concrete. Determination of cracking strength, ductility and residual tensile strength. Barcelona test. Spanish Association for Standardization and Certification, AENOR.

42. . Pujadas P., Blanco A., Cavalaro SHP., de la Fuente A., Aguado A. Multidirectional double punch test to assess the post - cracking behaviour and fibre orientation of FRC. Construction and Building materials 2014; 58:214-224.

43. A. Blanco, P. Pujadas, S.H.P. Cavalaro, A. de la Fuente y A. Aguado, "Constitutive model for fibre reinforced concrete based on the Barcelona test", Cement and Concrete Composites 2014; 54: 327340.

44. García M. (2012). Experimental program on concrete blocks subjected to concentrated loads. M.Sc. Thesis, Polytechnic University of Catalonia (UPC BarcelonaTECH), Barcelona (Spain). [In Spanish].

45. Bach, Carl (1903). Zeitschrift des Vereins Deutscher Ingenieure (Tests with granite articulations and Sandstone. Mitteilungen über Forschunsarbeiten. Publicados por la Asociación de Ingenieros Alemanes.

46. Sahoo, D.K.; Singh, B.; Bhargava, P. (2011). Minimum reinforcement for preventing failure in bottle-shaped struts. ACI Structural Journal, v. 108, no 2, pp. 206-216.

47. Infante, R.M. (2006). Evaluación de las Necesidades de Refuerzo de Armadura de las Dovelas Prefabricadas del Sostenimiento de la Línea 9 del Metro de Barcelona Sometidas al Empuje de la Tuneladora. Minor Thesis, Polytechnical University of Catalonia (UPC BarcelonaTECH), 126p.

48. Cavalaro, S.H.P., Aguado, A. (2012). Packer behavior under simple and coupled stresses. Tunnelling and Underground Space Technology, Volume 28, Pages 159-173

49. Sugimoto, M. (2006). "Causes of shield segment damages during construction". International Symposium on Underground Excavation and Tunnelling. Bangkok, Thailand. 
50. Mösrch E. (1952). Teoría y Práctica del Hormigón Armado. Ed. G. Gili S.A., Buenos Aires. 448 . 
ANNEX A. Tables with the parameters involved in the STM proposed models

Table A.1. Values of the parameters involved in the assessment of $\boldsymbol{F}_{c r}$ according to the STM proposed

\begin{tabular}{|c|c|c|c|c|c|c|c|c|c|c|c|c|}
\hline Specimen & $\begin{array}{l}k_{1} \\
{[]}\end{array}$ & $\begin{array}{c}a \\
(\mathrm{~mm})\end{array}$ & $\begin{array}{c}\boldsymbol{a}_{1} \\
(\mathrm{~mm})\end{array}$ & $\begin{array}{c}\boldsymbol{a}_{2} \\
(\mathrm{~mm})\end{array}$ & $\begin{array}{c}a_{3} \\
(\mathrm{~mm})\end{array}$ & $\begin{array}{c}q_{1} \\
\left(\mathrm{~N} / \mathrm{mm}^{2}\right)\end{array}$ & $\begin{array}{c}q_{2} \\
\left(\mathrm{~N} / \mathrm{mm}^{2}\right)\end{array}$ & $\begin{array}{c}\boldsymbol{b} \\
(\mathrm{mm})\end{array}$ & $\begin{array}{c}\boldsymbol{h}_{T} \\
(\mathrm{~mm})\end{array}$ & $\begin{array}{c}\boldsymbol{h} \\
(\mathrm{mm})\end{array}$ & $\begin{array}{c}f_{c t} \\
\left(\mathrm{~N} / \mathrm{mm}^{2}\right)\end{array}$ & $\begin{array}{c}F_{c r} \\
(\mathrm{kN})\end{array}$ \\
\hline PC-40-200-1.3 & \multirow{4}{*}{0.33} & 200 & \multirow{4}{*}{150} & - & - & - & - & \multirow{4}{*}{150} & \multirow{4}{*}{300} & 182 & \multirow{4}{*}{4,33} & 379 \\
\hline PC-40-250-1.7 & & 250 & & - & - & - & - & & & 233 & & 425 \\
\hline PC-40-400-2.7 & & 400 & & 89 & 400 & 15.92 & 8.27 & & & 370 & & 725 \\
\hline PC-40-750-5.0 & & 750 & & 90 & 405 & 16.57 & 8.12 & & & 376 & & 750 \\
\hline PC-50-200-1.3 & \multirow{4}{*}{0.33} & 200 & \multirow{4}{*}{150} & - & - & - & - & \multirow{4}{*}{150} & \multirow{4}{*}{300} & 182 & \multirow{4}{*}{4,09} & 358 \\
\hline PC-50-250-1.7 & & 250 & & - & - & - & - & & & 233 & & 401 \\
\hline PC-50-400-2.7 & & 400 & & 89 & 400 & 15.04 & 7.81 & & & 370 & & 685 \\
\hline PC-50-750-5.0 & & 750 & & 90 & 405 & 15.65 & 7.67 & & & 376 & & 708 \\
\hline SFRC-40-200-5.0 & \multirow{4}{*}{0.33} & 200 & \multirow{2}{*}{50} & - & - & - & - & \multirow{4}{*}{150} & \multirow{4}{*}{300} & 204 & \multirow{4}{*}{3,99} & 340 \\
\hline SFRC-40-250-4.0 & & 250 & & - & - & - & - & & & 260 & & 441 \\
\hline SFRC-40-400-2.7 & & 400 & \multirow{2}{*}{150} & 89 & 400 & 14.67 & 7.62 & & & 370 & & 668 \\
\hline SFRC-40-750-5.0 & & 750 & & 90 & 405 & 15.27 & 7.49 & & & 376 & & 691 \\
\hline SFRC-50-20-5.0 & \multirow{4}{*}{0.33} & 200 & \multirow{4}{*}{150} & - & - & - & - & \multirow{4}{*}{150} & \multirow{4}{*}{300} & 182 & \multirow{4}{*}{4,32} & 378 \\
\hline SFRC-50-25-4.0 & & 250 & & - & - & - & - & & & 233 & & 424 \\
\hline SFRC-50-40-2.7 & & 400 & & 89 & 400 & 15.88 & 8.25 & & & 370 & & 724 \\
\hline SFRC-50-75-5.0 & & 750 & & 90 & 405 & 16.53 & 8.11 & & & 376 & & 748 \\
\hline
\end{tabular}

Table A.2. Values of the parameters involved in the assessment of $\boldsymbol{F}_{\max }$ according to the STM proposed

\begin{tabular}{|c|c|c|c|c|c|c|c|c|}
\hline Specimen & $\begin{array}{l}k_{2} \\
{[]}\end{array}$ & $\begin{array}{c}a \\
(\mathrm{~mm})\end{array}$ & $\begin{array}{c}\boldsymbol{a}_{1} \\
(\mathrm{~mm})\end{array}$ & $\begin{array}{c}\boldsymbol{a}_{3} \\
(\mathrm{~mm})\end{array}$ & $\begin{array}{c}\boldsymbol{b} \\
(\mathrm{mm})\end{array}$ & $\begin{array}{c}\boldsymbol{h}_{T} \\
(\mathrm{~mm})\end{array}$ & $\begin{array}{c}f_{c} \\
(\mathrm{~mm})\end{array}$ & $\begin{array}{l}F_{\max } \\
(\mathrm{kN})\end{array}$ \\
\hline PC-40-200-1.3 & 0.59 & 200 & \multirow{4}{*}{150} & 200 & \multirow{4}{*}{150} & \multirow{4}{*}{300} & \multirow{4}{*}{43.7} & 980 \\
\hline PC-40-250-1.7 & 0.66 & 250 & & 250 & & & & 1003 \\
\hline PC-40-400-2.7 & 0.77 & 400 & & 400 & & & & 1156 \\
\hline PC-40-750-5.0 & 0.77 & 750 & & 405 & & & & 1162 \\
\hline PC-50-200-1.3 & 0.59 & 200 & \multirow{4}{*}{150} & 200 & \multirow{4}{*}{150} & \multirow{4}{*}{300} & \multirow{4}{*}{53.3} & 1195 \\
\hline PC-50-250-1.7 & 0.66 & 250 & & 250 & & & & 1223 \\
\hline PC-50-400-2.7 & 0.77 & 400 & & 400 & & & & 1409 \\
\hline PC-50-750-5.0 & 0.77 & 750 & & 405 & & & & 1417 \\
\hline SFRC-40-200-5.0 & 0.84 & 200 & \multirow{2}{*}{50} & 200 & \multirow{4}{*}{150} & \multirow{4}{*}{300} & & 431 \\
\hline SFRC-40-250-4.0 & 0.87 & 250 & & 250 & & & \multirow{3}{*}{39.4} & 500 \\
\hline SFRC-40-400-2.7 & 0.77 & 400 & \multirow{2}{*}{150} & 400 & & & & 1041 \\
\hline SFRC-40-750-5.0 & 0.77 & 750 & & 405 & & & & 1047 \\
\hline SFRC-50-200-5.0 & 0.59 & 200 & \multirow{4}{*}{150} & 200 & \multirow{4}{*}{150} & \multirow{4}{*}{300} & \multirow{4}{*}{51.8} & 1161 \\
\hline SFRC-50-250-4.0 & 0.66 & 250 & & 250 & & & & 1187 \\
\hline SFRC-50-400-2.7 & 0.77 & 400 & & 400 & & & & 1368 \\
\hline SFRC-50-750-5.0 & 0.77 & 750 & & 405 & & & & 1375 \\
\hline
\end{tabular}

